\title{
Backstepping Controller for Electrically Driven Flexible Joint Manipulator Under Uncertainties
}

\author{
Lilia Zouari*, Hafedh Abid**, and Mohamed Abid* \\ *Department of Electrical Engineering, Sfax University, CES laboratory, Tunisia \\ **Department of Electrical Engineering, Sfax University, Lab-STA, Tunisia
}

\begin{tabular}{l} 
Article Info \\
\hline Article history: \\
Received Feb 9, 2015 \\
Revised Apr 25, 2015 \\
Accepted May 12, 2015 \\
\hline Keyword: \\
Backstepping controller \\
BDCM motor \\
Flexible joint manipulator \\
Hysteresis controller. \\
Parameter uncertainties
\end{tabular}

\begin{abstract}
The grown complexity of the robot manipulators dynamics taking into account the joint flexibility, parameter uncertainties and unknown bounded disturbances makes conventional control strategies difficult and complex to synthesize. This paper focuses on the investigation into backstepping control of flexible joint manipulator driven by Brushless DC Motor (BDCM) in the presence of parameter uncertainties and unknown bounded disturbances for tracking trajectory. The goal of this paper is to compensate all uncertainties and disturbances for flexible join tmanipulator. To study the effectiveness of the controllers, backstepping controller has been developed for position control and an hysteresis controller has been treated for current control. Simulation results of the response of the flexible joint manipulators associated with their controllers have been presented. The high performances of the backstepping control are examined in terms of tracking accuracy and error reduction.
\end{abstract}

Copyright (0) 2015 Institute of Advanced Engineering and Science. All rights reserved.

\section{Corresponding Author:}

Lilia Zouari,

National Engineering Schools of Sfax, Soukra Road Km 3.5 Sfax, Tunisia.

lilia.zouari@ceslab.org

\section{INTRODUCTION}

The problem of tracking trajectory for flexible joint manipulator has received a considerable breakthrough in last decades. In fact, multiple applications necessitate using flexible joint manipulator such as space manipulators (1), manipulators used in the medicine and home automation fields(2). Besides, model uncertainties and bounded unknown disturbances can cause significant deviations between desired and real trajectories due to unknown or changing flexible joints or unmodelled dynamics or modelling errors $(3 ; 4)$. That's why; conventional or traditional controllers couldn't yield to good performance and dynamic behaviour(5). Recentattention has been including both flexible joints and actuator's dynamics to design control strategy to guarantee high performance in terms of tracking capability and attainable position. However, including actuator dynamics increases the system order, so the complexities to obtain robust control strategy. Infact, backstepping approach was used in multiple engineering fields such as electric machines and nonlinear systems especially robotic systems to benefit from its possibility to design robust nonlinear controllers that limit the effect of parameter uncertainties and unknown disturbances $(6 ; 7 ; 8)$.

Several researches have addressed the control of flexible joint manipulator using backstepping method cited the work done by Nicosia and Tomei (9). Besides, three types of backstepping controller based on exact model knowledge, adaptive controller to compensate parameter uncertainties and unknwon disturbances have been presented by Bridges et al (10). Moreover, an adaptive controller based on backstepping design has been proposed by Yim et al (11) and Oh et al (12). In this paper, the tracking problem for electrically driven flexible joint manipulator is studied unde runcertainties and disturbances. The main contribution of this paper is to extract an adequate and precise controller for flexible joint manipulator including the dynamic model of the BDCM which increases the complexity. This paper is organized as 
follows: in the second section, the flexible joint manipulator driven by Brushless DCMotor (BDCM) has been presented. In the thirds ection, both backstepping controller and hysteresis controller are studied respectively for controlling position and for controlling currents. In the fourth section, simulation results have been carried out in Simulink Matlab environment to show the performances of the different control techniques and their challenge to compensate uncertainties and disturbances.

\section{ELECTRICALLYDRIVENFLEXIBLEJOINTMANIPULATORMODEL} $14 ; 15 ; 16)$

The dynamics of a single flexible joint manipulator can be described by the following equations (13;

$$
\begin{array}{r}
x_{1}^{\prime}=x_{2} \\
x_{2}^{\prime}=-\frac{m_{1} g l_{1}}{J_{1}} \sin \left(x_{1}\right)-\frac{K}{J_{1}}\left(x_{1}-\frac{x_{3}}{\eta N}\right)+\frac{\Gamma_{d}}{J_{1}} \\
x_{3}^{\prime}=x_{4} \\
x_{4}^{\prime}=\frac{K}{J_{m}}\left(x_{1}-\frac{x_{3}}{\eta N}\right)+\frac{\Gamma}{J_{m}}
\end{array}
$$

Where

$\mathrm{x} 1=\mathrm{q}$ is the link position, $\mathrm{x} 2=^{\cdot} \mathrm{q}$ is the link speed, $\mathrm{x} 3=\Theta$ is the motor position, $\mathrm{x} 4=^{\cdot} \Theta$ is the motor speed, $\mathrm{m} 1$ is the link mass, $\mathrm{g}$ is the gravity, 11 is the link length, $\mathrm{J} 1$ is the link inertia, $\mathrm{Jm}$ is the motor inertia, $\mathrm{K}$ is the joint stiffness, $\Gamma$ is the torque applied to the axe, $\Gamma_{d}$ is the external torque, $\mathrm{N}$ is the reduction report, $\eta$ is the efficiency of the gearbox.

The model of the flexible articulation is composed of an engine torque control driving a load through a transmission box similar to a torsion spring of linear characteristic. In fact, most of mechanic system are not perfectly rigid and we should take flexibility into consideration in the dynamic model of the robot to be more near to the reality and analyze a more precise controller. In our case, the flexibilities are located at the joints and as in most of the time, we add springs in series with the transmission such as shown in the figure 1 .

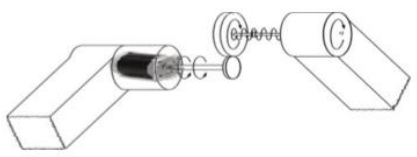

Figure 1. Flexible joint manipulator

\subsection{ActuatorModel}

The Brushless Direct Current Motor BDCM is a three phase synchronous motor. Using the inverter, we will supply the three motor coils such as shown in the Figure 2.

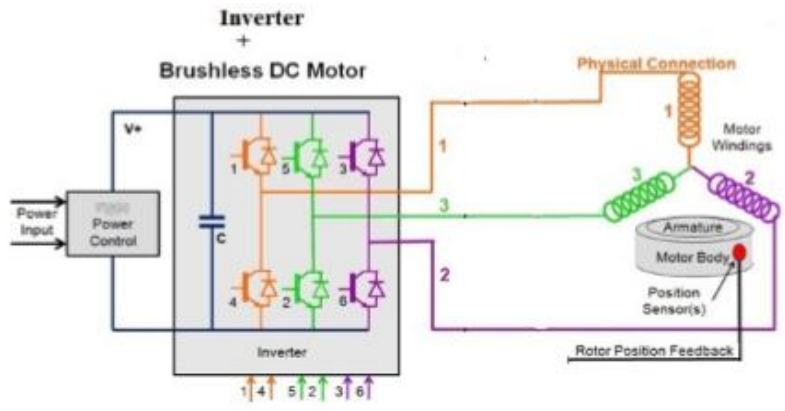

Figure 2. Inverter Brushless DC Motor (BDCM) association The electrical equation of brushless DC motor per phase is written as follows (17):

Backstepping Controller for Electrically Driven Flexible Joint Manipulator Under... (Lilia Zouari) 
Then,

$$
\frac{d I}{d t}=-\frac{R}{L} I+\frac{V-E}{L}
$$

expression:

the mechanical brushless DC motor equation is expressed by the following

$$
\frac{d \Omega_{m}}{d t}=-\frac{f}{J_{m}} \Omega_{m}+\frac{C_{e m}-C_{m}}{J_{m}}
$$

where:

a. E is the electromotive force (emf),

b. I is the current in the phases of motor,

c. Cem and $\mathrm{Cm}$ are the Electromagnetic and load torques of the motor respectively,

d. f represents the friction,

e. Jm is the inertia of the motor,

f. $\Omega \mathrm{m}$ is the velocity of the motor,

g. $\mathrm{V}$ is the tension in the phases of the motor,

h. L is the inductance of the motor,

i. $\mathrm{R}$ is the resistance of the motor,

j. KE and Kt are constants.

$\mathrm{k}$.

With $: \mathrm{E}=\mathrm{KE} \Omega \mathrm{m}$ and $\mathrm{Cem}=\mathrm{KtI}$

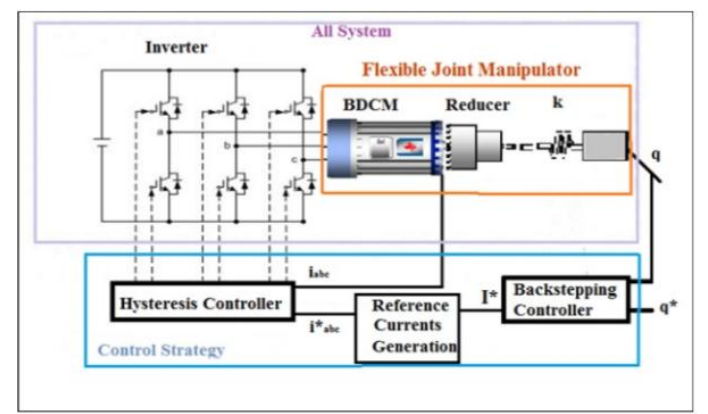

Figure 3. Flexible Joint Manipulator Control Strategy

\section{CONTROLSTRATEGY}

The control strategy implemented in the flexible joint manipulator driven by BDCM is given by Figure 3: The objective is to design a backstepping controller to remain the system behaviour to the desired trajectories, despite the presence of uncertainties and disturbances.

Table 1. Different Combination of the States of the Switches of a

\begin{tabular}{|c|c|c|c|c|c|c|c|c|c|c|c|c|}
\hline \multirow{2}{*}{$\begin{array}{l}\text { IGBT/ } \\
\text { diode }\end{array}$} & \multicolumn{2}{|c|}{ Sequence 1} & \multicolumn{2}{|c|}{ Sequence 2} & \multicolumn{2}{|c|}{ Sequence 3} & \multicolumn{2}{|c|}{ Sequence 4} & \multicolumn{2}{|c|}{ Sequence 5} & \multicolumn{2}{|c|}{ Sequence 6} \\
\hline & $\operatorname{seq}_{1}^{m}$ & $\mathrm{seq}_{1}^{g}$ & $\operatorname{seq}_{2}^{m}$ & $\mathrm{seq}_{2}^{\mathrm{g}}$ & $\operatorname{seq}_{3}^{m}$ & $\mathrm{seq}_{3}^{g}$ & $\mathrm{seq}_{4}^{m}$ & $\mathrm{seq}_{4}^{\mathrm{g}}$ & $\operatorname{seq}_{5}^{m}$ & $\operatorname{seq}_{5}^{g}$ & $\operatorname{seq}_{6}^{m}$ & $\operatorname{seq}_{6}^{g}$ \\
\hline S1 & OFF & OFF & ON & OFF & ON & OFF & OFF & OFF & $\overline{\mathrm{OFF}}$ & OFF & OFF & OFF \\
\hline S2 & OFF & OFF & OFF & OFF & OFF & OFF & $\mathrm{ON}$ & OFF & ON & OFF & OFF & OFF \\
\hline S3 & $\mathrm{ON}$ & OFF & OFF & OFF & OFF & OFF & OFF & OFF & OFF & OFF & ON & OFF \\
\hline S4 & OFF & OFF & OFF & OFF & OFF & OFF & OFF & OFF & ON & OFF & ON & OFF \\
\hline S5 & $\mathrm{ON}$ & OFF & $\mathrm{ON}$ & OFF & OFF & OFF & OFF & OFF & OFF & OFF & OFF & OFF \\
\hline S6 & OFF & OFF & $\mathrm{OFF}$ & OFF & $\mathrm{ON}$ & OFF & $\mathrm{ON}$ & OFF & OFF & $\mathrm{OFF}$ & OFF & OFF \\
\hline D1 & OFF & OFF & OFF & OFF & OFF & OFF & OFF & OFF & OFF & ON & OFF & ON \\
\hline D2 & OFF & $\mathrm{ON}$ & OFF & ON & $\mathrm{OFF}$ & OFF & OFF & OFF & OFF & OFF & OFF & OFF \\
\hline D3 & OFF & OFF & OFF & OFF & OFF & ON & OFF & ON & OFF & OFF & OFF & OFF \\
\hline D4 & OFF & OFF & OFF & ON & OFF & ON & OFF & OFF & OFF & OFF & OFF & OFF \\
\hline D5 & OFF & OFF & OFF & OFF & OFF & OFF & OFF & $\mathrm{ON}$ & OFF & ON & OFF & OFF \\
\hline D6 & OFF & $\mathrm{ON}$ & OFF & OFF & OFF & OFF & OFF & OFF & OFF & OFF & OFF & ON \\
\hline
\end{tabular}
Conventional Interver Associated with a BDCM 


\subsection{Hysteresis Controller}

The topology of the inverter is given by Figure 6. Each branch of the inverter includes two IGBTs and diodes connected on anti-parallel with them (18). Moreover, each sequence of the control signals of the the IGBTs S1-6 throughout a period is divided into active sub-sequence and regenerative sub-sequence (18).

A summary of the states of the switches (IGBTs and diodes) in the different sub-sequences (motor and generators) is given in the table 1 .

The outputs of the hysteresis controller determine the control signals for the IGBTs. Indeed, the principle of the hysteresis control is to maintain the measured current within a band of centered given width around the reference current Iref.

\subsection{Backstepping Controller}

The backstepping approach is a recursive design methodology. It involves a systematic construction of both feedback control laws and associated Lyapunov functions. The controller design is completed in a number of steps, which is never higher than the system order (n) $(16 ; 19)$. The system described by the equations 4 can be represented by the following generalized expression:

$$
\begin{gathered}
\dot{x_{i}}=f_{i}\left(x_{1}, \ldots x_{i}\right)+g_{i}\left(x_{1}, \ldots x_{i}\right) x_{i+1} \\
\dot{x_{n}}=f_{n}\left(x_{1}, \ldots x_{n}\right)+g_{n}\left(x_{1}, \ldots x_{n}\right) u
\end{gathered}
$$

where, $\mathrm{fi}(0)=0, \operatorname{gi}(0)=0,1 \leq \mathrm{i} \leq \mathrm{n}-1$ and $\mathrm{u}$ is the control law.

For each step (i), we consider $\mathrm{xi}+1$ as a virtual control input which is expressed as follows:

$$
\dot{x}_{i+1}=\frac{1}{g_{i}\left(x_{1}, \ldots x_{i}\right)}\left(u_{i}-f_{i}\left(x_{1}, \ldots x_{i}\right)\right)
$$

$$
\dot{x}_{i}=u_{i}
$$

The Lyapunov function is chosen to guarantee the asymptotically stability of the system for $(\mathrm{x} 1, \ldots, \mathrm{xi})=(0, \ldots, 0)$.

$$
V_{i}=V_{i-1}+\frac{1}{2}\left(x_{i}-\varphi_{i-1}\right)^{2}
$$

We choose also ui as follows:

$$
u_{i}=-\frac{\partial V_{i-1}\left(x_{1}, \ldots x_{i-1}\right)}{\partial x_{i-1}}-k_{i}\left(x_{i}-\varphi_{i-1}\right)+\sum\left(\frac{\partial \varphi_{i-1}}{\partial x_{l}} \dot{x}_{l}\right) ;
$$

where, $1 \leq \mathrm{l} \leq(\mathrm{i}-1) ; \mathrm{ki}>0$.

So, the virtual control input is expressed as follows:

$$
\dot{x}_{i+1}=\varphi_{i}=\frac{1}{g_{i}}\left(-\frac{\partial V_{i-1}\left(x_{1}, \ldots x_{i-1}\right)}{\partial x_{i-1}}-k_{i}\left(x_{i}-\varphi_{i-1}\right)+\sum\left(\frac{\partial \varphi_{i-1}}{\partial x_{l}} \dot{x}_{l}\right)-f_{i}\right.
$$

At the final stage, we can determine the actual control law un $=\varphi_{n}$ as follows:

$$
u_{n}=\frac{1}{g_{n}}\left(-\frac{\partial V_{n-1}\left(x_{1}, \ldots x_{i-1}\right)}{\partial x_{i-1}}-k_{n}\left(x_{n}-\varphi_{n-1}\right)+\sum\left(\frac{\partial \varphi_{n-1}}{\partial x_{l}} \dot{x}_{l}\right)-f_{n}\right.
$$

Where, $1 \leq \mathrm{l} \leq \mathrm{n}-1$ and $\mathrm{kn}>0$. 
The backstepping controller is determined by calculating the torque $u=\Gamma$. So, the states $x 1, x 2, x 3, x 4$ are controlled to origin point $(0,0,0,0)$, with the following four steps (16).

\subsubsection{Step1}

The first subsystem of 4 is:

$$
\dot{x_{1}}=f_{1}\left(x_{1}\right)+g_{1}\left(x_{1}\right) x_{2}
$$

Where,

$$
\begin{aligned}
& f_{1}\left(x_{1}\right)=0, \\
& g_{1}\left(x_{1}\right)=1 .
\end{aligned}
$$

The candidate Lyapunov function is chosen as follows:

$$
V_{1}=\frac{1}{2} x_{1}^{2}
$$

Then, the virtual control input $\mathrm{x} 2=\mathrm{u} 1$ is expressed as follows:

$$
x_{2}=u_{1}=\varphi_{1}\left(x_{1}\right)=-k_{1} x_{1}
$$

\subsubsection{Step2}

Considering $(\mathrm{x} 1, \mathrm{x} 2)$ of 4 is:

$$
\begin{aligned}
& \dot{x_{1}}=f_{1}\left(x_{1}\right)+g_{1}\left(x_{1}\right) x_{2} \\
& \dot{x_{2}}=f_{2}\left(x_{1}, x_{2}\right)+g_{2}\left(x_{1}, x_{2}\right) x_{3}
\end{aligned}
$$

Where

$$
\begin{aligned}
& f_{2}\left(x_{1}, x_{2}\right)=-\frac{m_{1} g l_{1}}{J_{1}} \sin \left(x_{1}\right)-\frac{K}{J_{1}}\left(x_{1}+\frac{\Gamma_{d}}{J_{1}},\right. \\
& g_{2}\left(x_{1}, x_{2}\right)=\frac{K}{\eta N I_{1}} .
\end{aligned}
$$

The candidate Lyapunov function is chosen as follows:

$$
V_{2}=V_{1}+\frac{1}{2}\left(x_{2}-\varphi_{1}\right)^{2}
$$

Then, the virtual control input $\mathrm{x} 3=\mathrm{u} 2$ is expressed as follows:

$$
x_{3}=\varphi_{2}\left(x_{1}, x_{2}\right)=\frac{\eta N J_{1}}{K}\left(\frac{\partial \varphi_{1}}{\partial x_{1}} \dot{x}_{1}-\frac{\partial V_{1}}{\partial x_{1}}-k_{2}\left(x_{2}-\varphi_{1}\right)-f_{2}\left(x_{1}, x_{2}\right)\right.
$$

\subsubsection{Step3}

Considering $(\mathrm{x} 1, \mathrm{x} 2, \mathrm{x} 3)$ of 4 is:

$$
\begin{aligned}
& \dot{x_{1}}=f_{1}\left(x_{1}\right)+g_{1}\left(x_{1}\right) x_{2} \\
& \dot{x_{2}}=f_{2}\left(x_{1}, x_{2}\right)+g_{2}\left(x_{1}, x_{2}\right) x_{3} \\
& \dot{x_{3}}=f_{3}\left(x_{1}, x_{2}, x_{3}\right)+g_{3}\left(x_{1}, x_{2}, x_{3}\right) x_{4}
\end{aligned}
$$


$f_{3}\left(x_{1}, x_{2}, x_{3}\right)=0$

$g_{3}\left(x_{1}, x_{2}, x_{3}\right)=1$. Where,

$V_{3}=V_{2}+\frac{1}{2}\left(x_{3}-\varphi_{2}\right)^{2}$

The candidate Lyapunov function is chosen as follows:

Then,

$x_{4}=\varphi_{3}\left(x_{1}, x_{2}, x_{3}\right)=\frac{1}{g_{3}}\left(u_{3}-f_{3}\right)$

the virtual control input $\mathrm{x} 4=\mathrm{u} 3$ is expressed as follows:

$x_{4}=\frac{\partial \varphi_{1}}{\partial x_{1}} \dot{x}_{1}+\frac{\partial \varphi_{2}}{\partial x_{2}} \dot{x}_{2}-\frac{\partial V_{2}}{\partial x_{2}}-k_{3}\left(x_{3}-\varphi_{2}\right)-f_{3}\left(x_{1}, x_{2}, x_{3}\right)$

\subsubsection{Step 4}

$\dot{x_{1}}=f_{1}\left(x_{1}\right)+g_{1}\left(x_{1}\right) x_{2}$

$\dot{x_{2}}=f_{2}\left(x_{1}, x_{2}\right)+g_{2}\left(x_{1}, x_{2}\right) x_{3}$

$\dot{x_{3}}=f_{3}\left(x_{1}, x_{2}, x_{3}\right)+g_{3}\left(x_{1}, x_{2}, x_{3}\right) x_{4}$

$\dot{x_{4}}=f_{4}\left(x_{1}, x_{2}, x_{3}, x_{4}\right)+g_{4}\left(x_{1}, x_{2}, x_{3}, x_{4}\right) u$

Where,

$$
f_{4}\left(x_{1}, x_{2}, x_{3}, x_{4}\right)=\frac{K}{J_{m}}\left(x_{1}-\frac{x_{3}}{\eta N}\right),
$$

$g_{4}\left(x_{1}, x_{2}, x_{3}, x_{4}\right)=\frac{1}{J_{m}}$.

The candidate Lyapunov function is chosen as follows:

$V_{4}=V_{3}+\frac{1}{2}\left(x_{3}-\varphi_{2}\right)^{2}$

Then,

$u=\Gamma=\frac{\partial \varphi_{1}}{\partial x_{1}} \dot{x}_{1}+\frac{\partial \varphi_{2}}{\partial x_{2}} \dot{x}_{2}+\frac{\partial \varphi_{3}}{\partial x_{3}} \dot{x}_{3}-\frac{\partial V_{3}}{\partial x_{3}}-k_{4}\left(x_{4}-\varphi_{3}\right)-f_{4}\left(x_{1}, x_{2}, x_{3}, x_{4}\right)$

the control law $\mathrm{u}=\Gamma$ is expressed as follows:

\section{SIMULATION RESULTS}

\subsection{Description of Simulation}

Table 2. System

\begin{tabular}{lll}
\hline Symbol & Description & Numeric Value \\
\hline$R$ & Resistance & $0.625 \Omega$ \\
$L$ & Inductance & $1.595 \mathrm{e}-3 \mathrm{H}$ \\
$J_{m}$ & Motor Inertia & $1 \mathrm{e}-5 \mathrm{Kg} \cdot \mathrm{m}^{2}$ \\
$m_{1}$ & Manipulator Mass & $0.8619 \mathrm{Kg}$ \\
$l_{1}$ & Manipulator Length & $0.3 \mathrm{~m}$ \\
$J_{1}$ & Manipulator Inertia & $0.0065 \mathrm{~N} . \mathrm{m}^{2}$ \\
$\mathrm{~N}$ & Reduction Report & 74 \\
$\eta$ & Gearbox Efficiency & 0.72 \\
$\mathrm{f}$ & Friction & $1.164 \mathrm{e}-3 \mathrm{Kg} \cdot \mathrm{m}^{2} . \mathrm{s}^{-} 1$ \\
$K_{t}$ & Torque constant & 0.0382 \\
$K_{E}$ & EMF constant & 0.0382 \\
& &
\end{tabular}

Parameters 

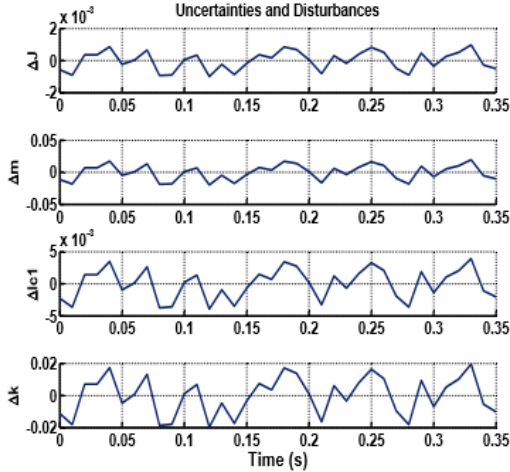

Figure 4. Evolution of Curves of the Parameter Uncertainties and Torque Disturbances

To illustrate the performance of backstepping control for flexible joint manipulator, we have simulated this algorithm in the simulink matlab environment. The system parameters used for simulation are given in table 2.

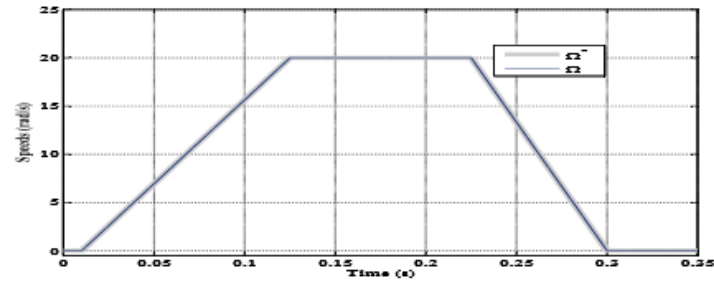

Figure 5. Evolution of the Speed

We have considered the uncertainties described in the following figure:

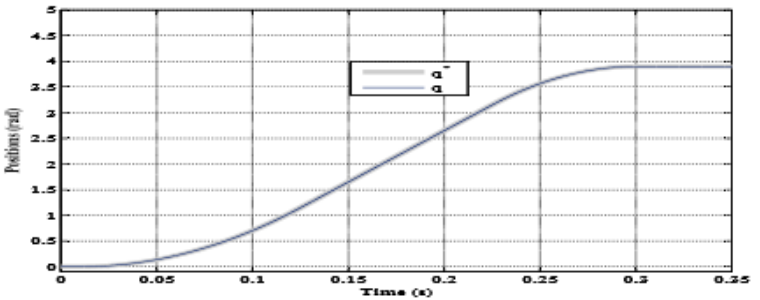

Figure 6. Evolution of the Position

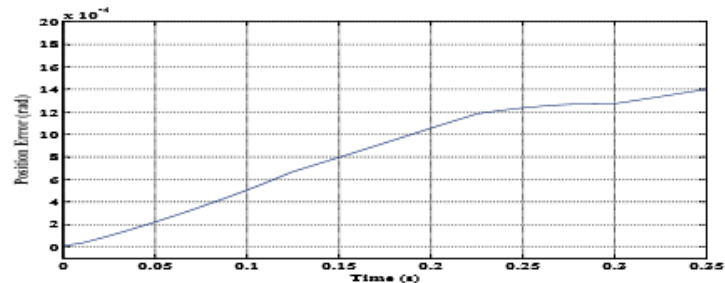

Figure 8. Evolution of the Position Error

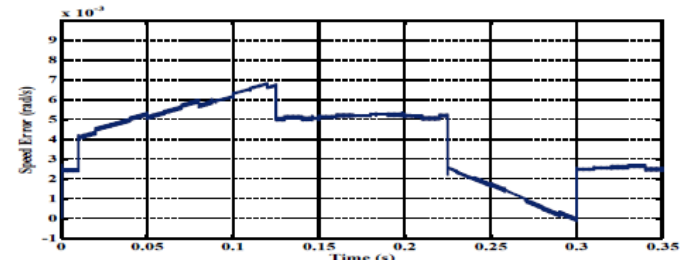

Figure 7. Evolution of the speed error

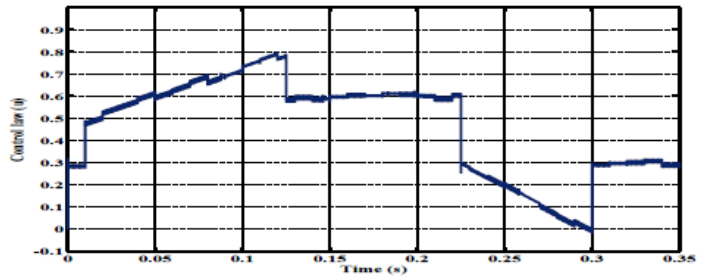

Figure 9. Evolution of the Control Law

\subsection{Simulation Analysis}

As can see from figures 5, 6, 7, 8 and 9, the behaviors of reference and actual tracking trajectory performance for different parameter uncertainties and bounded disturbances are very similar. Then, we can show that the variation of parameter uncertainties and bounded disturbances causes the apparition of ripples in the different curves behavior. The adopted control strategy allows us to compensate of all uncertainties and disturbances which prove the high performances of the backstepping control for tracking problem. 


\section{CONCLUSION}

Many control techniques have been designed to flexible joint manipulator control in the presence of uncertainties and disturbances. However, the performances of control strategy are degraded due to the negligence of actuator part. This paper presents backstepping and hysteresis controllers of flexible joint manipulator driven by Brushless DC Motor (BDCM) under uncertainties and disturbances for tracking problem. To study the effectiveness of the controllers, backstepping controller has been developed for position control and an hysteresis controller has been treated for current control. To evaluate the performances, we have implemented the control strategies in matlab simulink environment. The simulation results prove that the control strategies are robust against all uncertain ties and disturbances.

\section{REFERENCES}

[1]. Steve Ulrich and Jurek Z. Sasiadek, "Methods of Trajectory Tracking for Flexible Joint Space Manipulators", Preprints of the 18th IFAC World Congress, Milano (Italy), 2011.

[2]. Ali Reza Sahab and Mohammad Reza Modabbernia, "Backstepping Method For a Single-Link Flexible Joint Manipulator using Genetic Algorithm", International Journal of Innovative Computing, Information and Control. vol 7, no 7, July 2011. pp 4161-4170.

[3]. Hicham Chaoui, Wail Gueaieb, Mohammad Biglarbegian and Mustapha C.E.Yagoub, Computationally Efficient Adaptive Type-2 Fuzzy Control of Flexible-Joint Manipulators, Robotics 2013, vol 2, pp 6691.

[4]. Sung Jin Yoo, Jin Bae Park, and Yoon Ho Choi, Adaptive Dynamic Surface Control of Flexible-Joint Robots Using Self-Recurrent Wavelet Neural Networks, IEEE TRANSACTIONS ON SYSTEMS, MAN, AND CYBERNETICS-PART B: CYBERNETICS, VOL. 36, NO. 6, pp 1342-1355, DECEMBER 2006.

[5]. Mohammad Amin Rashidifar, Ali Amin Rashidifar, Darvish Ahmadi, Modeling and Control of 5DOF Robot Arm Using Fuzzy Logic Supervisory Control, International Journal of Robotics and Automation (IJRA), Vol.2, No.2, pp. 56-68, June 2013.

[6]. Rong Mei, Mou Chen, Robust Position Control of Electro-mechanical Systems, IAES TELKOMNIKA, Vol.11, No.3, pp. 1674-1681, March 2013.

[7]. He Jinbao, Yi Xinhua, Luo Zaifei, Li Guojun, Backstepping Decentralized Fault Tolerant Control for Reconfigurable Modular Robots, IAES TELKOMNIKA, Vol. 11, No. 7, pp. 3508-3516, July 2013.

[8]. Yongqiao Wei, Li Hou, Zhijun Sun, Fenglan Jia, BoLi, Backstepping Adaptive Fuzzy Schemefor SCARAGRB 400 Robot, IAES TELKOMNIKA, Vol. 11, No. 8, pp. 4229-4237, August 2013.

[9]. NICOSIA, Sand P.TOMEI (1992). Robot Controlby Using Only Joint Position Measurements, IEEET ransactions Automation Control 35 (1990) 1058-1061.

[10]. Bridges, M. M., D. M. Dawson and C. T. Abdallah (1995). Control of rigid-link, flexible-joint robots: a survey of backstepping approaches. Journal of Robotic Systems, pp 199-216.

[11]. W. Yim, Adaptive Control of a Fexible Joint Manipulator, Proc. of IEEE International Conference Robotics Automation, Seoul, Korea, pp. 3441-3446, May 2001.

[12]. Oh, J. H. and Lee, J. S., 1997. Control of Flexible Joint Robot System by Backstepping Design, Approach. Proc. of IEEE International Conference on Robotics Automation, pp. 3435-3440.

[13]. Mohd Ashraf Ahmad, Mohd Zaidi Mohd Tumari and Ahmad Nor Kasruddin Nasir. Composite Fuzzy Logic Control Approach to a Flexible Joint Manipulator, International Journal of Advanced Robotic Systems.

[14]. S. Ozgoli and H. D. Taghirad, A SURVEY ON THE CONTROL OF FLEXIBLE JOINT ROBOTS, Asian Journal of Control, Vol. 8, No. 4, pp. 332-344, December 2006.

[15]. Dong Hwan Kim and Won Ho Oh, Robust Control Design for Flexible Joint Manipulators: Theory and Experimental Verification, International Journal of Control, Automation, and Systems, vol. 4, no. 4, pp. 495-505, August 2006.

[16]. Ali Reza Sahab and Amir Gholami Pastaki, Optimal Controller with Backstepping and BELBIC for Single-Link Flexible Manipulator, World Academy of Science, Engineering and Technology, vol 55, 2011.

[17]. L.Bai, Electric Drive System with BLDC Motor, Proc. IEEE International Conference on Electric Information and Control Engineering (ICEICE), 2011.

[18]. L.Zouari, A.B.Rhouma, M.Abid. On the Potentialities of Reduced Structure Inverter Integrated in Robot Application. Proceedings of the World Congress on Engineering (WCE 2012), London, U.K, vol. 2, pp. 953-958,2012.

[19]. B. BROGLIATO, R. ORTEGA and R. LOZANOS, Global Tracking Controllers for Flexible-joint Manipulators: a Comparative Study, Automatica. vol. 31, no. 1, 1995, pp. 941-956. 